\title{
THE EFFECT OF THE USE OF TECHNOLOGICAL LUBRICANTS BASED ON VEGETABLE OILS ON THE PROCESS OF TITANIUM SHEET METAL FORMING
}

\begin{abstract}
The paper evaluates the drawability of titanium sheet metal Grade 2, with the focus on friction conditions that are present in the sheet metal forming process. The study aims to present the results of the examinations of the friction coefficient during a strip drawing test. The focus of the experiment was on lubricants based on vegetable oils i.e. rapeseed oil, sunflower oil and olive oil. Boric acid was used to improve the lubricating properties of vegetable oils. The results of numerical simulations of the process of forming a cover with stiffening components made of grade 2 titanium sheet metal was also presented. The numerical simulation was carried out using the FEM method with PAMStamp 2G software. The effect of conditions of friction between the sheet metal and tool parts and pressure force of the blank holder on the forming process were investigated. Numerical calculations were performed with consideration for the phenomenon of material strain hardening and anisotropy of plastic properties of the sheet metal formed. The analysis of the deformations and reduction in wall thickness of the drawn parts can be used for determination of the effect of changes in selected parameters on the process of drawn part forming. The quality of drawn parts was assessed based on the shape inaccuracy determined during simulation of forming. The inaccuracy depended on the conditions of the process and strength properties of the titanium sheet metal.
\end{abstract}

Keywords: sheet metal forming, tribological system, technical lubricant, numerical simulation FEM

\section{Introduction}

Nowadays, drawn parts made of sheet metal are required to show improved functional properties. A smooth surface without scratches, characterized by high stiffness and enhanced dimensional accuracy are often expected. These properties depend not only on the properties of the material formed but also on the method and conditions of the manufacturing process.

The empirical examinations of titanium sheet metal demonstrated substantial differences in material behaviour compared to steel sheet metal used in the stamping processes. Their formation represents a serious challenge for technologists, not only due to their limited capability of plastic deformation. Low strength parameters of Grade 2 titanium, unfavourable tribological properties, tendencies for build-up of the material on working surfaces of the tool, and, in the case of thin sheet metal, excessive reduction in the thickness and wrinkling of the material require an adequate design of the drawn parts and using technological lubricants [1-7]. Technological lubricants are used to prevent from a direct contact of the material with the tool, which leads to the build-up of the material growths on the tool surface. The growths are the major cause of scratches and indentations on the product, which cannot be removed in consecutive forming operations. Particularly in the case of forming of titanium sheet metal, the phenomenon of material build-up represents a serious problem which cannot be limited through application of specific lubricant compositions. Presence of lubricants leads additionally to a reduction in friction resistance, thus decreasing the intensity of tool wear [6, 8-10]. The lubricating ensures a smooth flow of material, leading to even deformations and smooth surface of the drawn parts. The essential characteristics that determine the usefulness of the processes of sheet metal forming also include: good washability and lack of corrosion effect of the lubricant on the drawn part, particularly during product storage. It is essential in the case of titanium sheet metal that the lubricant during formation in elevated temperature should protect the material formed from absorption of gases from the environment [11-14]. One of the most important physicochemical properties of lubricating oils that determine their quality is wettability. Wettability determines the intensity of lubricant absorption to the surface of the material formed or a tool.

Proper design of the process of forming of titanium drawn parts also requires solving the technological problems caused by the tendencies for elastic recovery, which affects dimensional accuracy and, consequently, quality of the products formed $[5,15,16]$.

Nowadays, the most of the above problems can be solved through combination of modern computer technology with experimental research. The effect of the technological lubricant on the process of titanium sheet metal (Grade 2) forming was evaluated based on the parallel experimental research and numerical

\footnotetext{
CZESTOCHOWA UNIVERSITY OF TECHNOLOGY, FACULTY OF MECHANICAL ENGINEERING AND COMPUTER SCIENCE, 69 DĄBROWSKIEGO STR., $42-200$ CZESTOCHOWA, POLAND Corresponding author: wieckowski@itm.pcz.pl
} 
simulations. The effect of the lubricant on the process of titanium sheet metal forming was evaluated based on the strip drawing test, which is very popular tool used in the forming technologies to determine the coefficient of friction [17-19]. Evaluation of the coefficient of friction allows for an effective analysis of the forming process while using numerical simulations. The in-depth analysis of the results of numerical simulations of the forming process allows for determination of forming parameters which are essential in terms of the quality of the drawn parts and forming parameters.

The problems connected with low drawability of sheet metal made of such materials as titanium can be eliminated through properly selected forming methodology, tool geometry, clamping force and ensuring adequate friction conditions. It seems that the last factor that may substantially facilitate the forming process is to use the right technological lubricant which ensures final products without defects.

\section{Goal and scope of work}

The aim of the study was to demonstrate, through experimental examinations, the effect of ecological oil-based lubricants on limitation of friction resistance during titanium sheet metal forming and to evaluate the effect of forming process parameters, including friction, on distribution of stress and strain in drawn parts using numerical simulations of the sheet metal forming performed using PAMStamp $2 \mathrm{G}$ software.

This study determined the coefficient of friction between the sheet metal formed and the tool by means of the strip drawing test. The test simulates the conditions of friction in the process of sheet metal forming. The examinations were conducted in the ambient temperature, for the same velocity and different surface pressure (see Fig. 1).

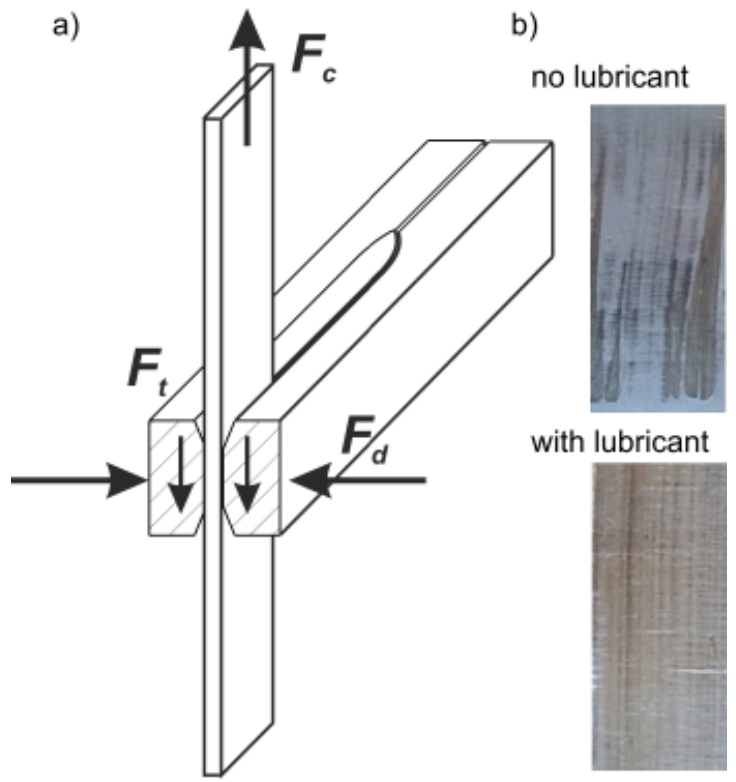

Fig. 1. Measurement of the coefficient of friction: a) design of the strip drawing test $F_{c}$-drawing force, $F_{d}$-clamping force, $F_{t}-$ friction force, b) view of the sheet metal surface after the drawing test
Material for experimental tests was provided by the Grade 2 titanium sheet metal. The tool was made of NC10 steel. The tests were performed in a dry friction environment i.e. without lubrication and in the presence of technological lubricants based on vegetable oils. Natural oils were examined: No. 1.01: rapeseed oil; No. 2.01: olive oil; No. 3.01: sunflower oil. Boric acid $\left(\mathrm{H}_{3} \mathrm{BO}_{3}\right)$ was also added to improve lubricating conditions. Due to the fact that boric acid is characterized by low solubility in oil, a new method to apply lubricant was used, as proposed in [20]. For comparison purposes, the examinations for the commercial oil-based lubricant (No. 4.01) were also conducted.

The experiment was supplemented with evaluation of wettability of the Grade 2 titanium sheet metal with oil-based vegetables and the commercial oil and evaluation of washability of lubricants from the surface of drawn parts.

Numerical simulations were conducted for the process of forming of titanium rectangular inspection hole cover with stiffening ribs. This design allowed for application of thinner sheet metal in the manufacturing process, thus reducing the mass without losing the strength and rigidity of the product. The cover was made of a thin grade 2 titanium sheet metal with thickness of $0.4 \mathrm{~mm}$. A drawn part with a flange was obtained using the forming process analysed in the study and the second step was flange trimming (see Fig. 2).
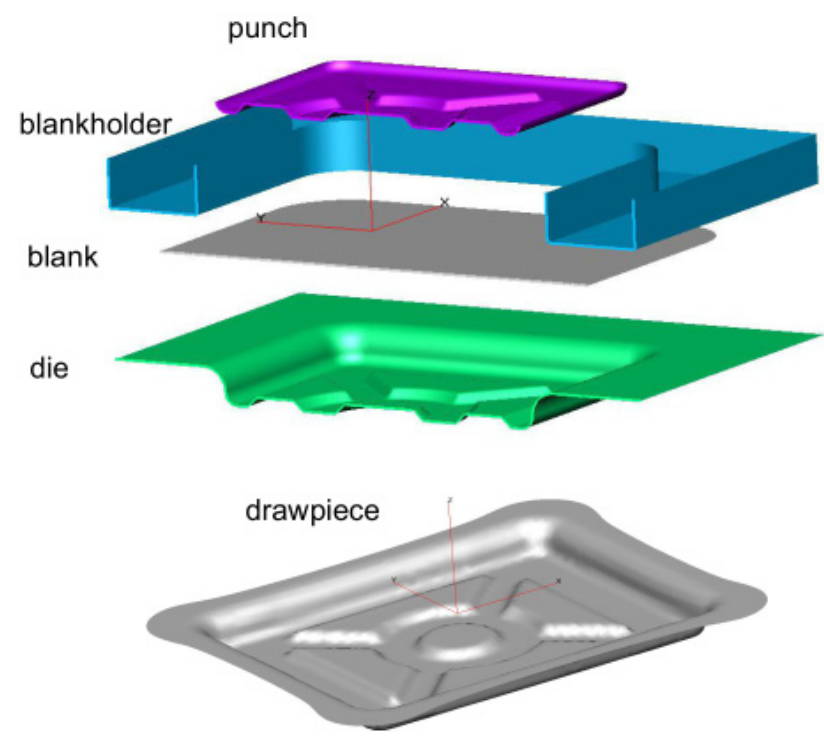

Fig. 2. Model of cover forming process

The simulations were performed for varied conditions of friction between the sheet metal and working surfaces of the tool, assuming the conditions of dry friction $\mu=0.4$, and lubrication $\mu=0.1$, with varied values of the blank holder force $F_{d}$ of 10 and $20 \mathrm{kN}$.

An elastic-plastic model with non-linear reinforcement was adopted for the material formed. Anisotropic strength properties were assumed for the sheet metal formed, in consideration for the Hill's elasticity law [21]. The mechanical properties of the Grade 2 titanium sheet metal necessary for calculations, including plastic strain ratio $r_{\alpha}$, were determined in the static uniaxial 
stretching test according to the PN-EN ISO 6892-1 standard and in the sheet metal strip tensile strength test with different orientation of axes with respect to rolling direction, according to PN-EN ISO 10113:2014-08 [21,22].

\section{Results}

The results of the examinations of the coefficient of friction in the strip drawing test for the steel-titanium friction pair are presented in Figs. 3 and 4. Figure 3 illustrates the effect of vegetable oils: rapeseed oil (No. 1.01), olive oil (No. 2.01) and sunflower oil (No. 3.01) on the coefficient of friction. For comparison purposes, the coefficient of friction was also examined with the presence of commercial oil based on mineral oil (No. 4.01). The diagrams show that application of vegetable oils led to a reduction in the coefficient of friction for the steel-titanium friction pair, from mean values of $\mu=0.49$ for dry friction to the level of $\mu=0.35$ for rapeseed oil (No. 1.01), mean $\mu=0.42$ for olive oil (No. 2.01) and mean $\mu=0.35$ for sunflower oil (No. 3.01). Furthermore, application of the mineral oil allowed for a reduction in the coefficient of friction to the mean value of $\mu=0.3$.

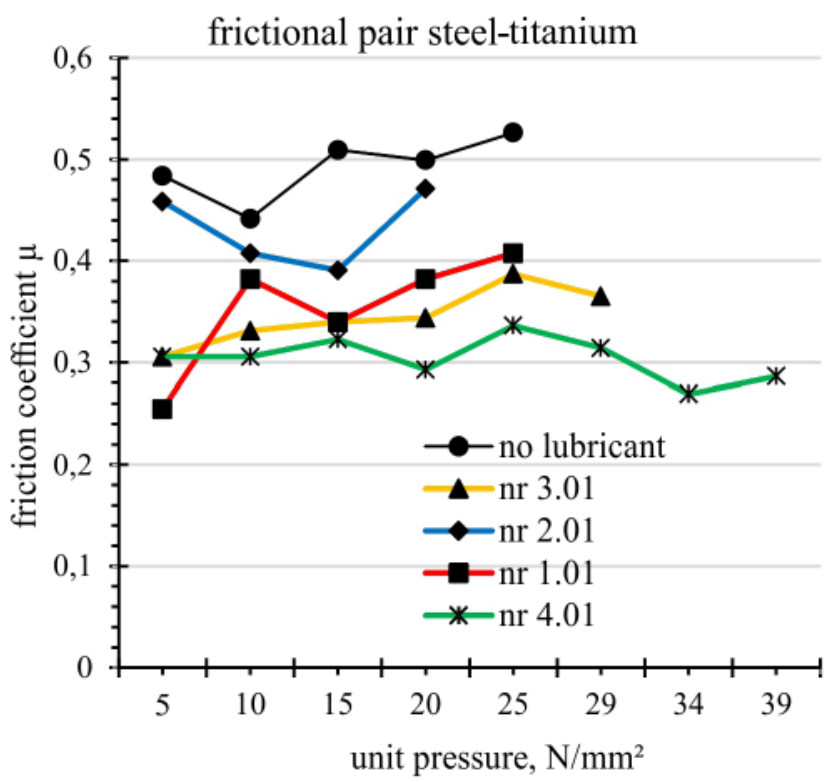

Fig. 3. Friction coefficients in presence of base oil as well as in dry condition for friction pair steel - titanium

Analysis of Figure 4 reveals that application of boric acid as a lubricating addition to vegetable oils led to a substantial reduction in the coefficient of friction, from the level of $\mu=0.49$ for dry friction to $\mu=0.07$ for rapeseed oil with $\mathrm{H}_{3} \mathrm{BO}_{3}$ (No. 1.11B), $\mu=0.05$ for olive oil with $\mathrm{H}_{3} \mathrm{BO}_{3}$ (No. 2.01B) and $\mu=0.06$ for the sunflower oil with $\mathrm{H}_{3} \mathrm{BO}_{3}$ (No. 3.01B).

The results of the experimental tests of forming titanium spherical caps presented in the study [23] demonstrated that the use of lubricants between the material formed and the die and blank holder allows for a more even flow of material, which is

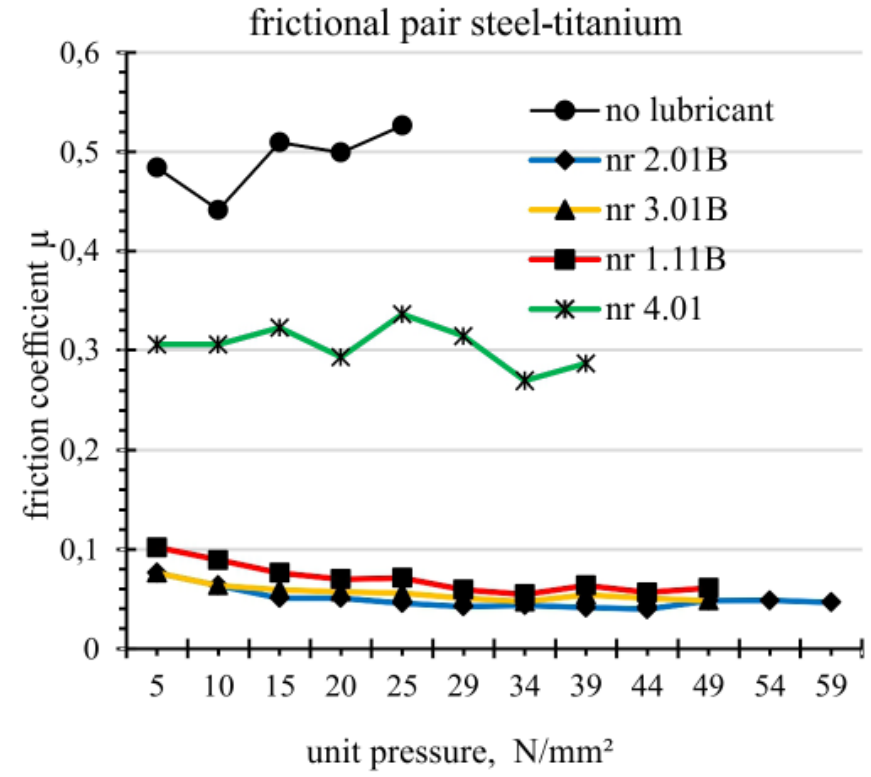

Fig. 4. The friction coefficients with film comprising base oil and boric acid for friction pair steel - titanium

reflected by a more even distribution of plastic strains and less intensive reduction in thickness of the sheet metal and leads to a reduction in the stamping force.

Evaluation of wettability of the Grade 2 titanium sheet metal with the base oils and the commercial oil was based on the measurement of the diameter of the drop of the lubricating oil applied on the surface of the sheet metal from the height of $10 \mathrm{~mm}$. The measurement was performed for 1 minute at $10 \mathrm{~s}$ intervals. Observations of the drop were conducted using the OPTA -TECH NSZ - 606 stereoscopic microscope. Greater diameters of the drop are observed for better surface wettability. Comparison of the diameters of drops of individual lubricants reveals that for the Grade 2 titanium sheet metal, olive oil No. 2.01 is characterized by the best wettability, whereas its lower value was found for the commercial oil 4.01.

The washability test performed for the vegetable oil-based lubricants, which consisted in evaluation of the fat stains on the filter paper after washing (with 5\% solution of a biodegradable detergent), did not show the stains on the filter paper, which means that the use of additional solvents, as it is the case for commercial oils, is not necessary.

The numerical simulations helped determine the distribution of plastic strain in the material of the drawn part and distribution of drawn part wall thickness. For each combination of the parameter of the stamping process, the drawn parts were obtained without the defects in the form of the losing material coherence. Figure 5 presents the results of numerical simulation of cover stamping for Grade 2 titanium under conditions of dry friction. The increase in the blank holder force allowed for formation of a drawn part without wrinkling and a strong tendency for wrinkling was observed only in the flange area. Without lubrication, the substantial part of points on the forming limit diagrams remains near the dangerous zone where the material is likely to lose its coherence. These points correspond to the 
areas with higher plastic strain on the surface of the drawn parts where a substantial reduction in the thickness of the sheet metal (Fig. 6) is observed.
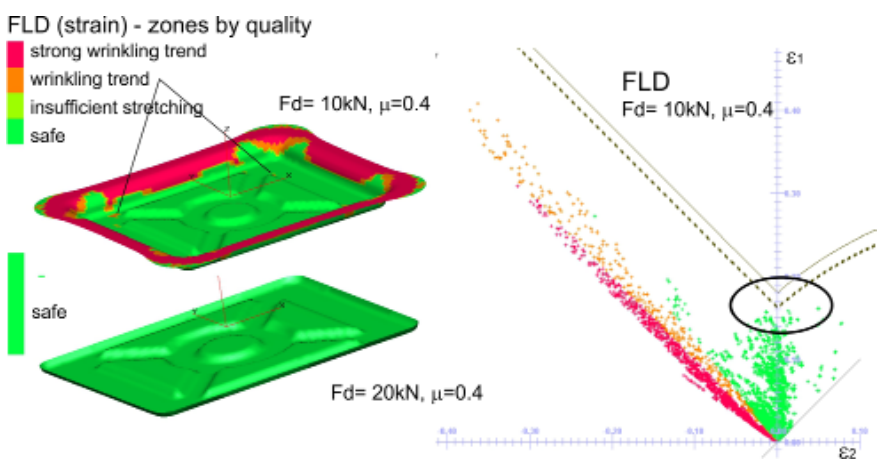

Fig. 5. Distribution of zones according to the quality on the surface of a drawn part under conditions of dry friction with forming limit diagram

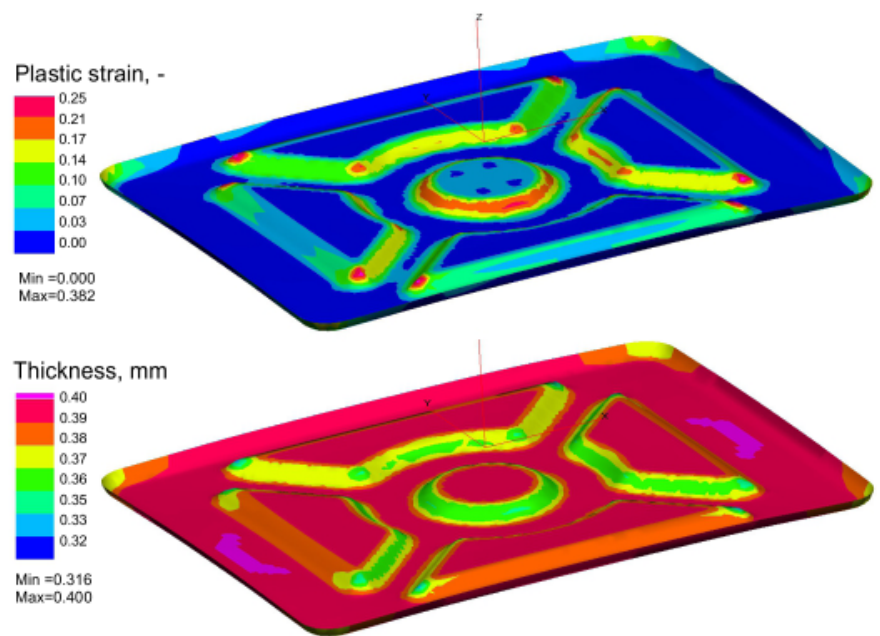

Fig. 6. Distribution of plastic strains and drawn part material obtained under conditions of dry friction and blank holder force of $F_{d}=20 \mathrm{kN}$

The highest values of plastic strain are observed in the corners of the drawn part and corners of the stiffening ribs and amount to 0.382 . The biggest thinning of the material was also observed in these areas, reaching $20 \%$ of the thickness of the formed sheet metal.

Reduction in the coefficient of friction on the surface of contact between material and tool helped reduce the risk of cracking of the material formed. However, material wrinkling in the area of the drawn part is likely to occur. This phenomenon intensifies for reduced values of the blank holder force (Fig. 7).

With unchanged blank holder force of $20 \mathrm{kN}$, application of a lubricant led to a reduction in deformations to the value of 0.275 and, consequently, limitation of reduction in the wall thickness (see Fig. 8).

As mentioned before, an important component that determined the quality of the drawn parts obtained in the study is dimensional accuracy. A deformation of the drawn part is observed at the stage of trimming of the flange, caused by the material springback. The level of the deformation of drawn parts was determined based on the deviation of points on the surface

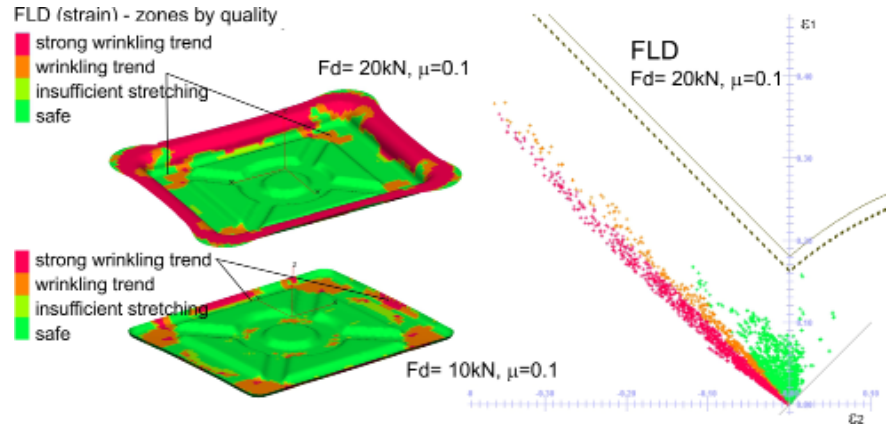

Fig. 7. Distribution of zones according to the quality for the surface of a drawn part under condition of lubrication with forming limit diagram

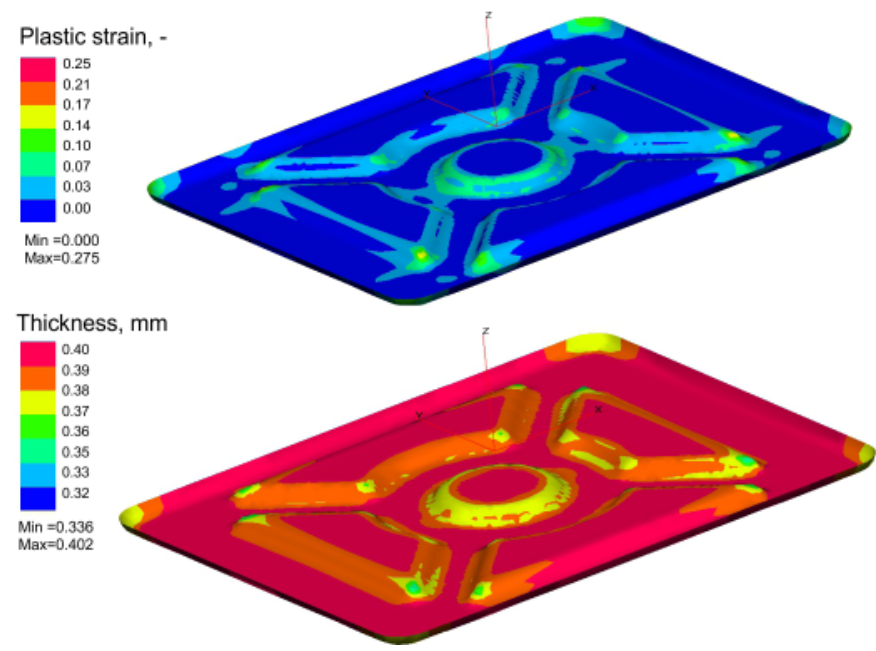

Fig. 8. Distribution of plastic strains and drawn part material thickness obtained under conditions of lubrication and blank holder force of $F_{d}=20 \mathrm{kN}$

of drawn part after operation of flange trimming from the assumed final shape of the product. The greatest deviations for the assumed geometry were found for the drawn part obtained under conditions of dry friction and blank holder force of $10 \mathrm{kN}$. These deviations occurred in the corners and were $0.959 \mathrm{~mm}$ (Fig. 9).

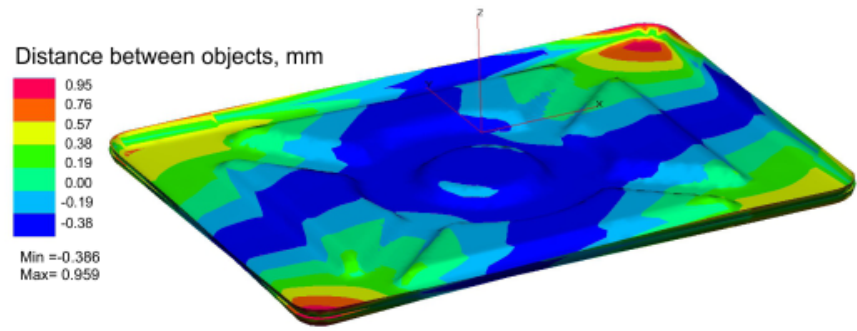

Fig. 9. Deformation of the drawn part obtained under conditions of dry friction, with blank holder force of $F_{d}=10 \mathrm{kN}$

The change in the forming process parameters affects both the character and intensity of drawn part deformation. The profiles and values of deformation in characteristic cross-sections of the drawn parts for the forming process variants analysed in the study are compared in Fig. 10. 

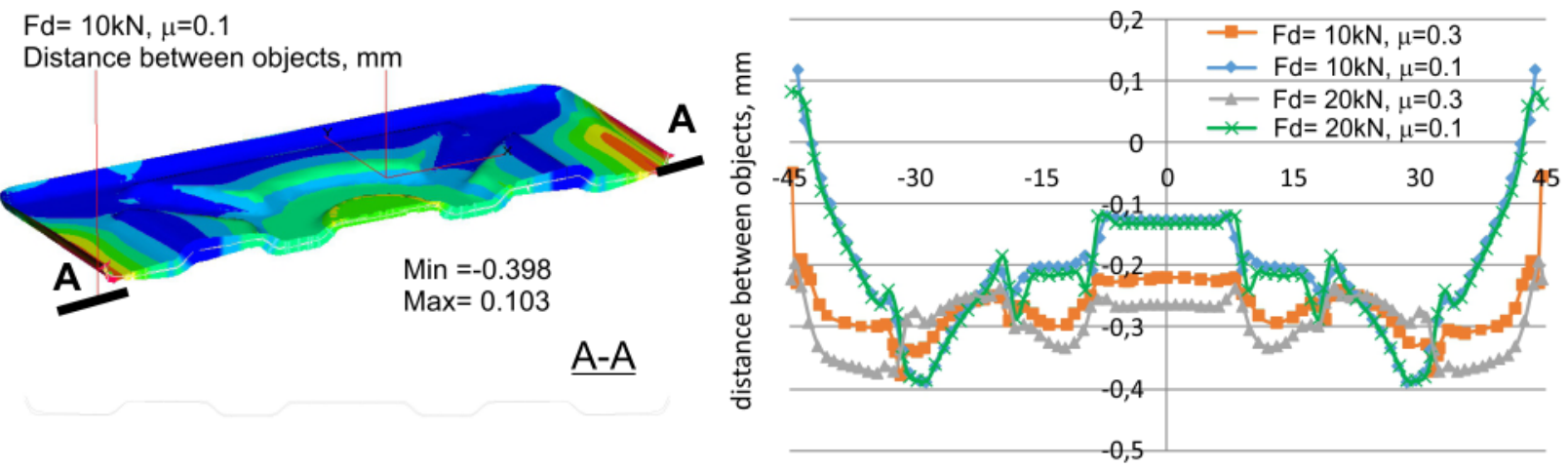

distance from the drawpiece center. $\mathrm{mm}$
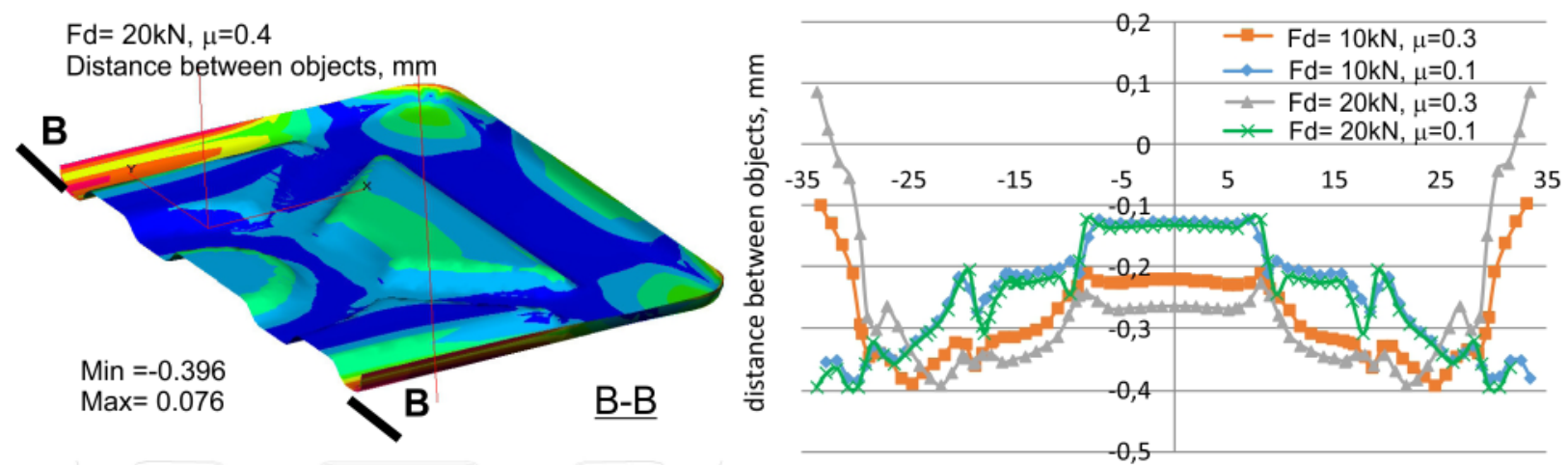

distance from the drawpiece center, $\mathrm{mm}$
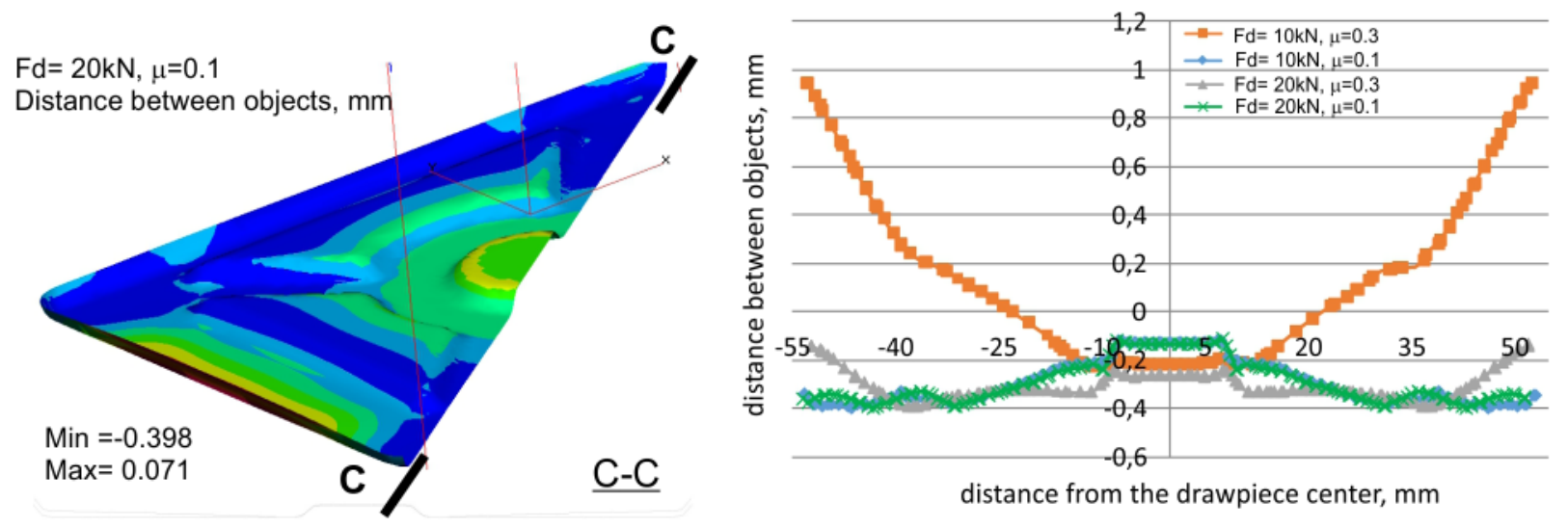

Fig. 10. Effect of process parameters on deformation in characteristic cross sections of the drawn part

\section{Summary}

It is essential during development of the lubricants for the plastic forming processes that, contrary to machine lubrication, where the lubricant remains in a closed system, the open friction pair is observed in the plastic working processes, which involves a much greater consumption of the technological lubricants. In the process of sheet metal forming, lubricant has to be always (i.e. after each operation) supplied to the friction pair. Its substantial part is "consumed" by the deformed material and remaining on the drawn part. Next, the lubricant is typically removed from the drawn part surface. Cleaning and disposal of lubricant waste is burdensome and cost-intensive. Therefore, the research on the effect of the use of technological lubricants in the sheet metal forming process should be focused on application of the natural environmentally-friendly lubricants. Therefore, lubricant substances that do not cause environmental pollution should be investigated. With regard to the above requirements, vegetable oil-based lubricants with addition of non-toxic boric acid seem to be a good solution.

In order to improve tribological conditions in sheet metal forming processes, it is necessary to separate the materials of the friction pair (i.e. tool and sheet metal material) by using technological lubricants. The attempts should be made not only to reduce friction resistance during forming but also to limit the tendency to build up material on the tool, especially in the case of titanium sheet metal forming.

The results of the examinations lead to the conclusion that the use of the popular and commercially available vegetable oils allowed for a reduction in the coefficient of friction for the steel-titanium friction pair. However, in this case, the commercial oil showed a better effect.

The use of ecological vegetable oils with addition of boric acid revealed a significant reduction in the coefficient of fric- 
tion $(\mu \approx 0.1)$ compared with commercial mineral oil for which $\mu \approx 0.3$ (No. 4.01).

Among the analysed base oils, the best wettability compared to Grade 2 titanium sheet metal was found for olive oil, which had also better adsorption capacity on the sheet metal surface compared to the commercial oil.

The numerical calculations demonstrated a significant effect of lubrication on distribution of strains in the volume of the material formed, which consequently translates into the quality of the drawn part depending on the changes in the thickness of the sheet metal and the deformation. Application of a lubricant reduces the risk of drawn part fracture. It also caused a more even distribution of plastic strain and less intensive reduction in sheet metal thickness, which, with the adequate blank holder force, has a positive effect on functional properties of the drawn part. However, a reduction in friction resistance elevates the risk of material wrinkling, caused by lower peripheral compressive stresses and excessive deformation of the drawn part after operation of flange trimming caused by the material springback effect.

\section{REFERENCES}

[1] J. Adamus, Key Eng. Mat. 410-411, 279-288 (2009).

[2] J. Adamus, International Journal of Applied Mechanics and Engineering 11, 4, 727-733 (2006).

[3] J. Adamus, Materials Engineering 30, 5, 310-313 (2009).

[4] J. Adamus, Metal Forming 19, 4, 29-36 (2008).

[5] J. Adamus, Tribologia 2, 15-24 (2008).

[6] K. Dyja, J. Adamus, Tribologia 3, 19-29 (2014).

[7] S. Kataoka, J. Kihara, T. Aizawa, Journal of the Japan Society for Technology of Plasticity 34, 385, 210-215 (1993).
[8] J. Adamus, Tribology-Plus 12th International Colloquium II, 1179-1182 (2000).

[9] J. Adamus, Technische Akademie Esslingen International Tribology Colloquium Proceedings III, 1813-1818 (2004).

[10] W. Więckowski, J. Adamus, Metal Forming 24, 3, 169-178 (2013).

[11] R. Marczak, Corrosion Protection 42, 496-503 (1999).

[12] J. Adamus, Analysis of forming titanium products by cold metal forming. Czestochowa University of Technology Publishing House, Monographs Series No 174, Czestochowa, Poland 2010.

[13] E. Hadasik, Analiza procesów przeróbki plastycznej stopów tytanu na podstawie badań plastometrycznych, Praca doktorska, Politechnika Ślaska, 1979.

[14] H.R. Le, M.P.F. Sutcliffe, Tribol. Int. 35, 123-128 (2002).

[15] J. Adamus, K. Dyja, W. Więckowski, Metal Forming 4, 24, $277-$ 286 (2014).

[16] J. Winowiecka, Metal Forming 3, 24, 219-231 (2013).

[17] H. Kim, T. Altan, Q. Yan, Evaluation of stamping lubricants in forming advanced high strength steels (AHSS) using deep drawing and ironing tests, J. Mater. Process. Tech. 209, 4122-4133 (2009).

[18] J.M. Pothier, J. Tribol. 28, 2, 414-421 (2006).

[19] V. Severob, L. Vilhenaa, P.N. Silvaa, J.P. Diasb, D. Beckerc, S. Wagnerc, A. Cavaleiroa, J. Mater. Process. Tech. 209, 10, 4662-4667 (2009).

[20] J. Adamus, W. Wieckowski, K. Dyja, J. Podlewski, Patent application no P.409887 dated 21.10.2014.

[21] Z. Marciniak, Odkształcenia graniczne przy tłoczeniu blach, WNT, Warszawa 1971.

[22] W. Więckowski, Key Eng. Mat. 687, 206-211 (2016).

[23] W. Więckowski, J. Adamus, K. Dyja, Rudy i Metale Nieżelazne 2, 61, 83-88 (2016). 